\title{
PENGARUH FAKTOR LEGALITAS RUMAH SAKIT, TAMPILAN FISIK, FASILITAS DAN TENAGA KESEHATAN TERHADAP MANAJEMEN MUTU RUMAH SAKIT TNI ANGKATAN LAUT SAMUEL J. MOEDA KUPANG
}

\author{
Muhammad H. Bennu', Marthen R. Pellokila², Masrida Sinaga ${ }^{3}$, \\ David. BW Pandie ${ }^{4}$ \\ ${ }^{1}$ Rumah Sakit TNI Angkatan Laut Samuel J. MOEDA Kupang \\ ${ }^{2}$ Sosial Ekonomi Pertanian, Faperta Undana \\ ${ }^{3}$ Administrasi dan Kebijakan Kesehatan, FKM Undana \\ ${ }^{4}$ Administrasi Publik, FISIP Undana
}

Dinyatakan Layak Publikasi :

Kupang, 29 Januari 2019

\begin{abstract}
$\mathcal{A B S T \mathcal { T A K }}$
Manajemen mutu merupakan bagian penting dalam peningkatan pelayanan kesehatan di Rumah Sakit dan setiap fasilitas layanan kesehatan wajib melaksanakan dengan baik secara secara optimal.

Tujuan penelitian ini untuk mengkaji faktor - faktor dalam manajemen mutu Rumah Sakit TNI Angkatan Laut Samuel J. Moeda Kupang sehingga bisa menjadi Rumah sakit terakredit agar dapat meningkatkan mutu dalam pelayanan di Rumah Sakit. Aspek legalitas menunjukkan rumah sakit belum memiliki perizinan yang lengkap. Aspek tampilan fisik menunjukkan kondisi bangunan serta pengaturan penempatan ruangan belum memenuhi syarat. Aspek fasilitas menunjukkan kekurangan sarana dan pemamfaatannya belum maksimal dan alat kesehatan menunjukkan masih kekurangan alat dan banyak alat yang rusak serta belum dikalibrasi. Aspek tenaga kesehatan menunjukkan terdapat kekurangan dokter dan apoteker serta tenaga bidan dan tenaga medis lainnya. Disarankan kepada pihak Rumah Sakit TNI Angkatan Laut untuk memenuhi perizinan rumah sakit, memperbaiki kondisi fisik bangunan, menyediakan dan memanfaatkan sarana dengan baik dan memperbaiki serta mengkalibrasi alat kesehatan, mengatasi kekurangan tenaga kesehatan, serta pemenuhan hak dan kewajiban pasien yang semuanya dapat dilakukan dengan dukungan Tentara Nasional Indonesia Angkatan laut maupun kerja sama dengan Lembaga Non Pemerintah.
\end{abstract}

Kata kunci : Pengetahuan, Komitmen Manajemen, Kesiapan Rumah sakit, Akreditasi, Mutu Rumah Sakit

\section{$\mathcal{A B S T R \mathcal { T C T }}$}

The Quality manegement in an important part in the improvement service health to Hospital and every healt sevice facility in orther that must to give the good service healt.

The aim of this study was to analize the factors to quality manajement of Samuel J.Moeda Navy Hospital in Kupang. This research is a qualitative research. Informants in this study were 15 people selected by purposive sampling method. The result shows that Sameul J. Moeda Navy Hospital in Kupang is not ready to heald National Healt Insurance in 2014. Based on the hospital legally aspect, not all the health wrkers have complete legal permit and practise license. Based on the physical aspect, it shows the condition of hospital building is not eligible and damaged. Based on the facility aspect, it does not have enough facilities and the information facility does not use as it must be used. Based on the health worker aspect, it shows that there is shortage of general doctor, specialist and pharmacist. Based on the medicine aspect, it shows incomplete availibility of medicine. Based on the medical aspect, it shows incomplete availability of medicine. Based on the medical tool aspect, it indicates unpreparedness of hospital because there are many broken tool and it not been calibrated.

It is recommended to the Samel J. Moeda Navy Hospital Samuel J. Moeda in Kupang to complete the hospital licensing, repair the physical condition of the building, provide and utilize the pacilities well, overcome the shortage of helath worker, fix and calibrate medical tools, do patient satisfaction measurement. All the recommendations can be done throuht the partnership with neither central Navy nor Non-Goverment Organization.

Key words: Knowledge, Management Commitment, Readiness Of Hospital, Accreditation, Quality Management. 


\section{PENDAHULUAN}

Rumah sakit adalah salah satu perusahaan yang bergerak di bidang jasa, dimana dalam menjalankan kegiatannya diperlukan tenaga kerja cukup banyak yang menguasai teknologi, alat-alat medis, pelayanan fasilitas dan sarana yang memadai, penyediaan makanan, peralatan serta sistem manajemen administrasi yang terkoordinasi dengan baik, karena pelayanan dengan mutu atau kualitas yang terbaik akan dipilih oleh para pasien (UU No.44 tahun 2009). Tujuan pelayanan kesehatan adalah tercapainya derajat kesehatan masyarakat yang memuaskan harapan dan kebutuhan derajat masyarakat .Upaya peningkatan mutu pelayanan kesehatan adalah langkah terpenting untuk meningkatkan daya saing usaha Indonesia di sektor kesehatan.

Gamrin (2014) menyatakan dalam hasil penelitiannya bahwa adanya masalah serius dalam mutu pelayanan kesehatan di Indonesia. Hal ini disebabkan karena belum adanya sistem pengendali mutu yang terbaik yang dapat diterapkan. Saat ini terdapat 2.228 rumah sakit di Indonesia. Diharapkan bahwa semua rumah sakit dapat terakreditasi sehingga bisa menjaga mutu pelayanan Ruamh Sakit. Di Provinsi Nusa Tengara Timur (NTT), dari 42 rumah sakit baik milik pemerintah daerah maupun TNI/POLRI, yang merupakan jaringan pelayanan dari PT. ASKES Persero berjumlah 31 rumah sakit (Askes, 2012). Hingga 1 Januari 2016 rumah sakit yang telah lulus akreditasi di NTT berjumlah 26 rumah sakit tidak termasuk didalamnya R.S TNI AL Samuel J. Moeda (Kemenkes, 2015). Rumah sakit TNI AL Samuel J. Moeda Kupang merupakan suatu fasilitas kesehatan yang juga tidak terlepas dari permasalahan.

Rumah Sakit (RS) TNI AL Samuel J. Moeda sejak tahun 2015masih mengalami beberapa permasalahan seperti kurangnya ketenagaan dokter spesialis. Sampai saat ini RS TNI AL Samuel J. Moeda baru memiliki tiga dokter spesialis tetap (Penyakit Dalam, Bedah dan Danesthesi). Disamping kekurangan tenaga dokter, tenaga perawat, dimana sampai saat ini baru memiliki 53 orang tenaga perawat untuk ruang perawatan 89 tempat tidur. Sesuai Peraturan Menteri Kesehatan nomor 262 untuk R.S Kelas C, tenaga perawat perbandingannya $2: 3$ (jumlah tempat tidur : tenaga). Masalah lain yaitu kekurangan gedung pelayanan seperti gedung isolasi, ruang ICU, perawatan anak, linen/loundry, gedung apotik rawat inap, gedung genset serta kamar jenazah sehingga untuk sementara ruangan lain yang semestinya tidak dicampur dengan pasien, seperti ruang isolasi memakai satu dari ruang perawatan biasa sehingga ruangannya tidak terpisah dengan ruang pasien non infeksius, sehingga rentan penularan kepasien lain dan pengunjung pasien, Jumlah kunjungan pasien setiap tahunnya 12.456 orang terdiri dari 10.680 orang pasien rawat jalan dan 1.776 orang pasien rawat inap.Untuk BOR Rumah sakit TNI AL yaitu $42 \%$ dengan LOS 3 - 5 hari (Data Laporan Tahunan R.STNI AL 2015).

Data di atas menunjukkan adanya permasalahan urgensi pemenuhan mutu pelayanan rumah sakit sebagai syarat untuk dapat diakreditasi. Status terakreditasi adalah suatu kewajiban krusial bagi rumah sakit untuk menyelenggarakan pelayanan 
kesehatan yang sesuai standar denganasas keadilan, terutama dalam menerima pelayanan dengan strata fasilitas kesehatan dan kebutuhan medik yang sama dapat terlayani bagi seluruh masyarakat. Dasar pikir inilah yang mendorong untuk penelitian ini dilakukan.

\section{METODE PENELITIAN}

Jenis penelitian yang digunakan adalah penelitian survey deskriptif dengan menggunakan pendekatan kualitatif. Penelitian kualitatif digunakan untuk menyelidiki, menemukan, menggambarkan dan menjelaskan keistimewaan dari pengaruh sosial yang tidak dapat dijelaskan, diukur atau digambarkan melalui penelitian kuantitatif. (Suryono dan Anggreani,2010). Penelitian dilaksanakan Rumah Sakit TNI AL Samuel J. Moeda, Kelurahan Namosain, Kecamatan Alak, Kota Kupang berlangsung dari bulan Januari sampai Pebruari 2017 . Konsep dalam penelitian kualitatif berkaitan dengan memilih informan atau situasi sosial tertentu yang dapat memberikan informasi yang akurat dan terpercaya mengenai elemenelemen yang ada. Berdasarkan kriteria diatas, maka informan dalam penelitian ini sebanyak 15 orang, seperti disajikan dalam Tabel 1.

Tabel 1. Karakteristik Informan berdasarkan Umur, Jabatan dan Masa Kerja di Rumah Sakit TNI AL Samuel J. Moeda Tahun 2017.

\begin{tabular}{lcclc}
\hline No & Inisial & $\begin{array}{c}\text { Umur } \\
\text { (tahun) }\end{array}$ & \multicolumn{1}{c}{ Jabatan } & $\begin{array}{c}\text { Masa } \\
\text { Kerja }\end{array}$ \\
\hline 1 & JK & 41 & Direktur & 17 \\
2 & BD & 37 & Ka.Tata usaha & 14 \\
3 & MH & 36 & Kabag.Perawatan & 15 \\
4 & DD & 38 & Kabag.Prog.Anggaran & 15 \\
5 & IR & 34 & Kabag. Personalia & 17 \\
6 & WD & 26 & Kepala Bag.Klinik & 15 \\
7 & FT & 28 & Kepala Bag.Penunjang Klinik & 13 \\
8 & AR & 34 & Kepala Komite Medis & 9 \\
9 & MY & 39 & Kepala Subag.Radiologi & 13 \\
10 & ED & 35 & Kepala Subag.Laboratorium & 3 \\
11 & CH & 24 & Kepala Inst.IGD/Poliklinik & 11 \\
12 & MH & 29 & Ka.Satuan Markas & 18 \\
13 & YH & 28 & Karu bangsal dewasa & 13 \\
14 & OL & 27 & Karu bangsal anak/Kebidanan & 11 \\
15 & RT & 32 & Kasubag. Gizi & 10 \\
\hline Keterangan : Karakteristik Informan Berdasarkan Umur, Jabatan Dan Masa Kerja Di Rumah Sakit TNI AL
\end{tabular}

Teknik pengumpulan data dalam penelitian ini adalah wawancara mendalam dan observasi. Wawancara ini bertujuan untuk memperoleh berbagai informasi lebih mendalam tentang berbagai kondisi rumah sakit saat ini dan bentuk faktor - faktor 
dalam manajemen mutu rumah sakit. Observasi atau pengamatan dilakukan dengan alat bantu berupa checklist.

Analisis data dimulai dengan membuat transkrip semua informasi yang diperoleh baik dengan checklist, wawancara mendalam maupun catatan lapangan, kemudian mencari ide yang dimaksud informan berupa kata kunci dari setiap pernyataan. Kumpulan pernyataan yang ada digarisbawahi pernyataan dan kata kuncinya yang penting agar mudah dikelompokkan sesuai setiap konteks atau variabel penelitian. Setelah itu melakukan interpretasi data dan kemudian disajikan dalam bentuk narasi dan tabel.

\section{HASIL DAN PEMBAHASAN}

\section{Aspek Legalitas}

Hasil wawancara menunjukan bahwa sampai tahun 2017, pihak RS TNI AL Samuel J. Moeda Kupang sebagian wilayah rumah sakit belum memiliki izin mendirikan rumah sakit dan sementara izin operasional sudah dimiliki, walaupun masih berupa izin operasional sementara yang diberikan oleh Pemerintah Daerah Kota Kupang. Disamping itu juga belum memiliki ijin mendirikan bangunan RS TNI. Surat penetapan kelas RS, Rumah Sakit belum mempunyai sertifikat akreditasi, dan belum semua tenaga kesehatan memiliki Surat Izin Praktek (SIP) dan Surat Tanda Registrasi (STR).

Tabel 2. Distribusi Tenakes RS TNI AL Samuel J. Moeda Kupang berdasarkan Kepemilikan STR dan Kepemilikan SIP/SIB

\begin{tabular}{|c|c|c|c|c|c|}
\hline \multirow{2}{*}{ No } & \multirow{2}{*}{ Tenaga Kesehatan } & \multicolumn{2}{|c|}{ Kepemilikan STR } & \multicolumn{2}{|c|}{ Kepemilikan SIP/SIB } \\
\hline & & Ya & Tidak & Ya & Tidak \\
\hline 1 & Dokter Spesialis Antap & 1 & - & 1 & - \\
\hline 2 & Kontrak & 2 & - & 1 & 1 \\
\hline 3 & Dokter Umum Mil & 2 & - & 2 & - \\
\hline 4 & Kontrak/ Interenship & 2 & 6 & 2 & 6 \\
\hline 5 & Dokter Gigi Mil & 1 & - & 1 & - \\
\hline 6 & Kontrak & 1 & - & - & 1 \\
\hline 7 & Perawat Mil/PNS & 18 & - & 7 & 11 \\
\hline 8 & Honor & 9 & 26 & 15 & 20 \\
\hline & Jumlah & 36 & 32 & 29 & 39 \\
\hline
\end{tabular}

Keterangan : Data Primer Kepemilikan SIP dan STR Tenaga Kesehatan di R.S TNI AL Tahun 2016

\subsection{Legalitas Rumah Sakit}

Legalitas atau keabsahan rumah sakit merupakan hal mutlak yang wajib dimiliki oleh sebuah rumah sakit supaya dinyatakan lulus kredensialing dan akreditasi. Dengan dinyatakannya Rumah Sakit terakreditasi maka Rumah Sakit memenuhi standar mutu sesuai permenkes 2012. Peenuhan surat izin operasional (izin operasional sementara) dan terdapatnya Surat Izin Praktek (SIP) tenaga kesehatan (dokter, perawat, bidan, apoteker) wajib dilengkapi. Ketidaklengkapan perizinan di RS TNI AL Samuel J. Moeda Kupang apabila dikaji dalam sisi 
perizinan rumah sakit, maka hal ini dikatakan tidak sesuai dari aturan yang ada (Permenkes Nomor 147/Menkes/Per/I/2010 tentang Perizinan Rumah Sakit). Berikut kutipan wawancara dengan Direktur R.S TNI AL Kupang :

" Untuk masalah perijinan,iyaa memang sih masih ada beberpa suratnya yang belum punya seperti ijin operasional, surat penetapan kelas, dan sertifikat akreditasi.tapi sementara beberapa sudah dalam tahap penguirusan sih" (SR)

Lisensi (perizinan) merupakan suatu proses pemberian izin oleh pemrintah kepada individu dan/atau lembaga pelayanan kesehatan untuk melaksanakan misinya. Regulasi lisensi dikembangkan untuk menjamin bahwa individu dan/atau lembaga pelayanan kesehatan tersebut telah memenuhi standar minimal untuk memenuhi standar politik dan tenaga kesehatan. Secara perizinan R.S TNI AL Samuel J. Moeda Kupang memang belum memenuhi berbagai syarat, namun bukan berarti tanpa upaya untuk mendapatkan akreditasi nantinya. Salah satu aspek yang juga penting saat sebuah rumah sakit mempersiapkan diri menyelanggarakan JKN adalah kepemilikan SIP bagi tenaga kesehatan. Kepemilikan SIP didahului oleh kepemilikan STR oleh tenaga kesehatan. Berdasarkan Permenkes Nomor 161/Menkes/Per/I/2010 tentang Registrasi Tenaga Kesehatan maka setiap tenaga kesehatan (untuk peneliian ini adalah dokter, perawat, bidan dan apoteker serta tenaga penunjang medis) diwajibkan untuk memiliki STR. Selain STR, SIP juga merupakan sebuah bukti diizinkannya tenaga kesehatan untuk melakukan praktek difasilitas kesehatan. Berdasarkan data primer yang dikumpulkan dari setiap instalasi, belum semua tenaga kesehatan memiliki STR dan SIP.

Implikasi dari kepemilikan SIP dan STR adalah pada tanggung jawab rumah sakit untuk menyelenggarakan pelayanan kesehatan secara legal dan berkualitas, dalam hal ini menghindari terjadinya medical error di rumah sakit. Apabila terjadi medical error akibat keidaksengajaan maupun kesengajaan tenaga medis, maka pasien tentunya dapat mempertanyakan mengajukan keluhan terhadap hal tersebut. Wahyudi dalam publikasinya terkait tanggung jawab rumah sakit terhadap kerugian pasien karena kelalaian tenaga medis menulis bahwa terdapat 3 akibat, yakni pembinaan kerja, sanksi hukum pidana dan penggantian kerusakan pasien, dimana sebelum sampai pada keputusan tersebut salah satu yang perlu ditindaklanjuti aspek legalitas dari tenaga kesehatan itu sendiri. Oleh karena itu, kepemilikan SIP dan STR berguna sebagai salah satu rambu atau pedoman agar tenaga kesehatan dapat berpraktik secara legal dan berkualitas sehingga dapat menghindari berbagai resiko kelainan tenaga medis. Dengan demikian, pasien dapat menerima pelayanan yang berkualitas dan tenaga medis sendiri memiliki kualifikasi dan legalitas untuk berpraktik. Belum lengkapnya aspek perijinan di Rumah Sakit ini dapat terlihat dari hasil cheklist yang diambil dari data manajemen yang terangkum dalam tabel dibawah ini

Aspek legalitas rumah sakit sejalan dengan aspek medikolegal, dimana rumah sakit harus dapat memberikan perlindungan dan kepastian hukum bagi seluruh tenaga kesehatan yang memberikan pelayanan kesehatan di rumah sakit melalui 
pembentukan berbagai perangkat aturan rumah sakit meliputi, peraturan internal staf medis, standar prosedur operasional dan berbagai pedoman pelayanan kesehatan serta melalui penyediaan SDM yang memiliki kompetensi dalam bidang medikolegal. Hal lain yang perlu mendapat perhatian bersama oleh seluruh pihak di rumah sakit adalah menyangkut pelaksanaan etika profesi dan etika rumah sakit sehingga penyelenggaraan Pelayanan secara beretika akan sangat mempermudah seluruh pihak dalam menegakkan aturan-aturan hukum (Kemenkes, 2011)

\subsection{Aspek Tampilan Fisik}

Rumah Sakit TNI AL Samuel J. Moeda Kupang yang berdiri sejak 2008 memiliki total 11 bangunan termasuk bangunan utama perkantoran dan pelayanan itupun masih sifatnya terbatas karena masih gedung penunjang lainnya yang belum ada (profil RS TNI AL Samuel J. Moeda Kupang Tahun 2016). Bangunan Pelayanan Rawat Jalan/UGD berdasarkan hasil observasi, ruang poliklinik terdiri dari 3 buah poli, yakni poli umum, poli spesialis dan poli fisioterapi, namun kesemuanya ini tergabung dalam ruangan dengan menggunakan gedung perkantoran staf karena samapai sekarang ini RSAL belum mempunyai gedung poliklinik jadi untuk sementara masih menggunakan gedung kantor staf sehingga ruangan yang ada sangat terbatas. Termasuk Ruang laboratorium, apotik dan radiologi juga bermasalah karena Luas gedung tidak mencukupi serta fasilitas ruangan penempatan tidak sesuai. Berikut merupakan kutipan wawancara dengan Kepala Satuan Markas R.S TNI AL Kupang :

"Memang untuk sementara ruang poli kita dengan ruang staf masih jadi satu, ini karena kita mengalami keterbatasan ruangan jadi kita manfaatkan ruangan yang ada dulu. Sekarang masih menunggu dari pusat untuk pembangunan gedung untuk poliklinik biar kedepan bisa kita pisah." $(\mathrm{CH})$

Bangunan Ruang Perawatan teruatama bangsal dewasa sekarang ini ruangan perawatan RS TNI AL Samuel J. Moeda Kupang Dari pengamatan untuk sementara belum mempunyai ruang isolasi, ruang perawatan tidak dilengkapi dengan ruang tindakan sehingga menyulitkan petugas untuk memberi tindakan, termasuk juga bangsal Anak masih digabung dengan bangsal Obgin karena ruangan terbatas. Secara umum, apabila dibandingkan dengan Pedoman Penyelenggaraan Pelayanan Kesehatan di Rumah Sakit (Depkes, 2008) maka didapati bahwa lokasi rumah sakit sudah sesuai, yakni mudah dijangkau karena terletak di poros jalan .

Dampak lain terkait luas ruangan yang tidak mencukupi adalah pelayanan yang kurang maksimal karena pasien merasakan ruangan tersebut cukup sempit. Walupun ruangan terasa cukup sejuk tapi butuh waktu lama untuk mendapatkan tindakan sehingga pasien juga merasakan terganggu dan merasa kurang nyaman. Seperti yang terlihat diruang Laboratorium akibat ruangan sempit sehingga tempat mengambil sampel cuma satu kursi saja. Jadi pasien harus antri dengan waktu yang lumayan untuk mendapatkan giliran. Hal ini tentunya berkaitan dengan kenyamanan pasien. Dalam penelitian Alfi Fauziah An-Nafi (2009) di RS UI Kustati Surakarta 
diketahui bahwa ada pengaruh kenyamanan lingkungan fisik di ruang rawat inap terhadap kepuasan pasien. Di samping itu, penempatan ruangan juga sangat berdampak pada pelayanan pasien, dengan tergabungnya poli umum dengan ruang staf sehingga sangat rentan dengan penularan penyakit yang ada di poli kepada staf, termasuk diruang rawat inap, dampak digabungnya dalam satu gedung antara ruangan non infeksius dengan kelas utama ataupun rawat inap kelas 2 maka itu juga rentan terhadap timbulnya nosokomial dirumah sakit.

\subsection{Aspek Sarana}

Sarana transportasi untuk kepentingan pelayanan ambulan terdiri dari 2 mobil ambulans dan 1 mobil jenazah. Kondisi 1 mobil ambulan rusak serta Rumah Sakit tidak dilengkapi dengan mobil operasional sehingga seringkali mobil kereta merta atau mobil ambulans tersebut dipakai untuk sebagai mobil operasional. Akibat pemakaian yang berlebihan yang bukan pada tujuannya sehingga membuat kondisi mobil cepat rusak Berikut ini merupakan kutipan wawancara dengan Kepala Satuan Markas R.S TNI AL Kupang:

"Dua (ambulan) yang ada Cuma 2 tapi satunya rusak parah jadi otomatis yaa Cuma satu yang berfungsi melayani pasien.Kita juga kereta merta tapi keretamerta ini mempunyai fungsi ganda disamping untuk nagnter jenazah juga seringkali digunakan sebagai mobil operasional.tapi tetap pelayanan kepasien kita utamakan dulu." (JU)

Sarana sanitasi di RS TNI AL Samuel J. Moeda Kupang masih sangat terbatas, untuk sarana air bersih memanfaatkan dari PDAM, cuma karena suplai debit dari PDAM juga sangat terbatas sehingga sementara masih mengandalkan mobil tanki Dengan adanya keterbatasan air ini sehingga air tidak mengalir 24 jam. Rumah sakit juga belum punya alat incenerator sehingga pengolahan sampah medis padat masih pake cara bakar manual.

Hasil observasi menunjukan bahwa ketersediaan alat kesehatan rumah sakit juga terbatas yakni pemeriksaan dasar saja seperti darah rutin dan kimia darah sedangkan pemeriksaan penunjang lainnya belum ada .Untuk alat kesehatan X Ray, pelayanan kesehatan yang dapat dilaksanakan untuk pemeriksaan radiologi di RS TNI AL Samuel J. Moeda Kupang yakni pemeriksaan thorax, skull, cervical, thorakal, lumbal, pelvis, antebrahi, manus, femur, cruris dan angkel joind sedangka alat-alat: dental $x$-ray, mobile unit $x$-ray, G100C rad $x$-ray belum ada.Alat diagnostik USG juga belum ada dan beberapa alat kesehatan lainnya yang harus ada di Rumah sakit tipe C seperti ,set operasi kecil, set operasi besar, meja operasi standar, alat bedah dan sebagainya. Berikut hasil wawancara kepala IGD sebagai berikut :

"Ketersediaan alat UGD juga memang belum terlalu lengkap karena masih banyak alat - alat UGD yang masih dalam tahap pengajuan. Ada bebrapa alatnya ada tapi dalam keadaan rusak seperti alat pacu jantung kita dalam keadaan rusak,

sebenarnya diajukan untuk perbaikan tapi samapi sekarang belum


terealisasi,sedangkan diRumah sakit sendiri kita belum punya tehnisi khsusus untuk perbaikan alat - alat ini'(MAP)

Dari aspek sarana yang ada di rumah sakit, belum semuanya tersedia dan memenuhi standar. Namun pihak rumah sakit tetap berupaya untuk menyelenggarakan yang terbaik semampunya mereka.

Sarana transportasi dalam hal ini ambulans yang tersedia di RS TNI AL Samuel J. Moeda Kupang sangat kurang. Dalam format kredensialing, ambulan harus memiliki kelengkapan peralatan medis seperti tabung $\mathrm{O}_{2}$, tandu dan sebagainya, sedangkan kondisi saat ini, ambulan jenazah tidak memiliki peralatan yang lengkap. Perencanaan tahun 2017 yang oleh pihak RS TNI AL Kupang, diupayakan agar dapat diadakan 1 ambulan transportasi dan 1 ambulan jenazah untuk mempermudah pelayanan ambulan kepada pasien. Sarana sanitasi yang dimaksud adalah penyediaan air bersih untuk kebutuhan rumah sakit, sarana pengolah limbah dan insenerator. Penyediaan air bersih juga terkait pengawasan kualitas air minum sehingga perlunya dilakukan inspeksi sanitasi air minum 1 tahun sekali dan pemeriksaan kimia air minum dan air bersih sekurang-kurangnya 2 tahun sekali. Aspek kredensialing akreditasi RS tidak membahas mendalam tentang penyediaan air bersih secara kualitas, namun PAB di rumah sakit harus menjadi perhatian penting karena dapat menjadi salah satu media penularan penyakit. Dengan demikian, pengukuran kualitas air dapat dilakukan untuk mencegah hal-hal yang mengganggu atau memperparah kondisi kesehatan.

Sarana sanitasi lainnya adalah sarana pembuangan limbah baik itu limbah padat maupun limbah cair. Sarana pembuangan sampah padat dan saluran untuk limbah cair dari instalasi radiologi, Laboratorium dan Linen serta kamar mandi pasien. Dari daftar personil tidak ada satupun pengawak/pengelola IPAL di Rumah Sakit dengan kualifikasi dari kesehatan lingkungan sehingga secara personal sangat rentan dalam hal pengawasan karena penempatan personil bukan pada bidangnya.

Pembuangan sampah padat di RS TNI AL Samuel J. Moeda Kupang yakni langsung dari setiap ruangan lalu didistribusi untuk dibakar di tempat pembungan akhir. Tidak terdapat insenerator di Rumah sakit sehingga sampah padat yang ada semuanya dibakar di lingkungan terbuka. Dampak pencemaran daratan dapat secara langsung dan tidak langsung bagi kesehatan lingkungan sekitar. Penyakit-penyakit yang ditimbulkan dengan perantaraan tikus, lalat dan nyamuk di antaranya pest, kaki gajah, malaria, demam berdarah dan sebagainya. Berdasarkan hasil observasi dan wawancara, pihak R.S TNI AL Samuel J. Moeda Kupang sedang berupaya untuk merencanakan dan membangun Incenerator yang baru karena ini salah satu syarat untuk akreditasi. Apabila dibandingkan dengan kondisi normatifnya maka, sarana sanitasi yang ada belum memenuhi syarat.

Beroperasinya pelayanan di R.S TNI AL Kupang, ditunjang energi listrik sekitar 52 KVA dan genzet berkapasitas $60 \mathrm{KVA}$. Idealnya kalau dihitung dengan kebutuhan pada beban puncak harus minimal 65 KVA. Berdasarkan Pedoman Penyelenggaraan Kesehatan di Rumah Sakit (Depkes, 2008), maka sumber energi 
listrik di R.S TNI AL Samuel J. Moeda Kupang belum memenuhi syarat, dengan terpenuhinya kebutuhan energi listrik maka sudah memenuhi syarat yang menyediakan sumber energi

Sarana komunikasi dan informasi yakni belum tersedianya papan pengumuman sehingga dapat mengurangi berbagai informasi yang harus ditempelkan pada jendela di berbagai ruangan. Dampak yang dirasakan oleh pasien adalah terkadang pasien sendiri tidak dapat mendapatkan informasi yang dibutuhkan.

Alat kesehatan merupakan bagian yang penting dalam penyelenggaraan pelayanan kesehatan di rumah sakit. Berdasarkan Permenkes nomor 71 tahun 2013 tentang Pelayanan Kesehatan pada JKN pasal $26: 2$ mengatakan "Fasilitas kesehatan dan jejaringnya wajib menyediakan alat kesehatan yang dibutuhkan oleh peserta sesuai indikasi medis" Dukungan alat yang sudah ada tidak dibarengi dengan pemeliharaan yang baik. Keadaan ini terjadi karena terkendala biaya pemeliharaan yang kecil sehingga kegiatan pemeliharaan maupun perbaikan sarana belum berjalan maksimal.Pengujian dan kalibrasi serta perbaikan peralatan kesehatan sejalan dengan program peningkatan mutu pelayanan kesehatan kepada masyarakat, seperti yang diamanatkan oleh Undang-Undang Nomor 44 Tahun 2009 tentang Rumah Sakit.

UU No.44 2009, pada pasal 16 ayat 2 menegaskan bahwa peralatan medis harus diuji dan dikalibrasi secara berkala oleh Balai Pengujian Fasilitas Kesehatan dan/atau Institusi Penguji yang Berwenang. Kondisi ini akan berdampak pada pasien karena hasil pemeriksaan dengan alat kesehatan yang belum dikalibrasi bisa saja mengalami kesalahan yang berakibat pada diagnose medis kepada pasien. Berbagai kondisi seperti kalibrasi alat dan adanya alat vital yang rusak berdampak pada patient safety. Aspek sarana yang bagus dan peralatan kesehatan yang memadai maka memberikan jaminan pelayanan yang berkualitas sesuai dengan standar mutu kepada pasien sehingga dapat memberikan rasa keadilan bahwa semua pasien harus mendapatkan pelayanan yang sama tanpa terkecuali.

\subsection{Aspek Tenaga Kesehatan}

Permenkes Nomor 340/Menkes/Per/III/2010 tentang Klasifikasi Rumah Sakit, maka sebuah rumah sakit kelas $\mathrm{C}$ minimal memiliki 4 dokter spesialis dasar, 9 orang dokter umum dan 2 dokter gigi sebagai tenaga tetap, harus ada masing-masing minimal 4 orang dokter spesialis dari 4 pelayanan spesialis dasar dengan 2 orang spesialis sebagai tenaga tetap. Standar jumlah tenaga keperawatan adalah perbandingan tenaga keperawatan dengan tempat tidur adalah 2:3, sedangkan untuk standar jumlah apoteker di rumah sakit kelas C menurut Depkes tahun 2008 adalah minimal 4 orang. Tenaga kesehatan yang terdapat di R.S TNI AL Samuel J. Moeda Kupang dapat dilihat pada Tabel 3.

Tabel 4.3 menunjukkan bahwa tenaga kesehatan paling banyak adalah perawat sedangkan yang paling sedikit adalah dokter gigi dan apoteker. Berdasarkan hasil penelitian dokter umum yang aktif menjalankan tugas di R.S TNI AL Samuel J. Moeda Kupang sebanyak 2 orang karena 1 orang dokter sedang melanjutkan pendidikan spesialis serta terdapat 6 dokter internship namun sebentar lagi akan 
mengakhiri masa interenshipnya pada bulan Juni tahun 2017. Pemenuhan standar jumlah tenaga kesehatan di R.S TNI AL Samuel J. Moeda Kupang menjadi perhatian penting, terutama untuk dokter umum, dokter spesialis medik dasar dan apoteker, sebagaimana dapat dilihat dari hasil

Tabel 3. Data Jumlah Tenaga Kesehatan Berdasarkan Status Kepegawaian di R.S TNI AL Samuel J. Moeda KupangTahun 2016

\begin{tabular}{llcc}
\hline \multirow{2}{*}{ No } & \multicolumn{2}{c}{ Tenaga Kesehatan } & \multicolumn{2}{c}{ Status Kepegawaian } \\
\cline { 3 - 4 } & Dokter Spesialis & 2 & PNS/Mil \\
2 & Dokter Umum & 2 & 6 \\
3 & Dokter Gigi & 1 & 1 \\
4 & Apoteker & 1 & 1 \\
5 & Bidan & 2 & 1 \\
6 & Perawat & 18 & 35 \\
7 & Asisten apoteker & 1 & 1 \\
8 & Radiografer & - & 1 \\
9 & Analis & - & 3 \\
\hline & Jumlah & 27 & 50 \\
\hline Sumber : Data Primer Tahun 2016
\end{tabular}

Pihak R.S TNI AL Samuel J. Moeda Kupang telah berupaya unuk memenuhi tenaga kesehatan terutama dokter umum dan dokter spesialis medik dasar, dengan mengadakan kerjasama sebagai dokter tamu/dokter konsulen sehingga bisa mengisi kekosongan dokter spesialis yang ada, begitupun dengan dokter umum, rumah sakit rencana akan mengangkat dokter kontrak untuk mengisi dokter umum yang kosong. Berikut merupakan kutipan wawancara bersama Direktur R.S TNI AL Kupang :

"Kalau untuk mengisi kekosongan dokter spesialis maka kita minta bantuan teman - teman dokter spesialis yang ada dirumah sakit lain sebagai dokter konsulen, jadi kalau ada pasien dirawat baru kita konsulkan. Karena kalau mau sistem kontrak kita tidak punya anggaran kecuali dokter umum kita kasi semacam uang duduk sekitar Rp.1.000.000 perbulan diluar jasa perpasien jadi masih terjangkau"(MD)

Berdasarkan Permenkes Nomor 340/Menkes/Per/III/2010 tentang Klasifikasi Rumah Sakit, maka sebuah rumah sakit kelas $\mathrm{C}$ minimal memiliki 4 dokter spesialis dasar, 9 orang dokter umum dan 2 dokter gigi sebagai tenaga tetap, harus ada masing-masing minimal 4 orang dokter spesialis dari 4 pelayanan spesialis dasar dengan 2 orang spesialis sebagai tenaga tetap. Standar jumlah tenaga keperawatan adalah perbandingan tenaga keperawatan dengan tempat tidur adalah $2: 3$, sedangkan untuk standar jumlah apoteker di rumah sakit kelas C menurut Depkes tahun 2008 adalah minimal 4 orang.

Beban kerja dokter umum di R.S TNI AL Samuel J. Moeda Kupang tergolong tinggi karena hanya terdapat 2 orang dokter umum. Dengan adanya beban kerja yang tinggi tiap hari tetapi kinerja baik dapat memberikan dampak pada dokter tersebut di kemudian hari, karena tidak selamanya daya tahan tubuh manusia akan selalu bertahan pasti akan terjadi penurunan daya tahan tubuh. Beban kerja yang 
terlalu berlebihan akan menimbulkan berbagai efek yakni kelelahan baik fisik maupun mental dan reaksi-reaksi emosional seperti sakit kepala, gangguan pencernaan, kelalaian, lupa dan mudah marah sehingga secara potensial membahayakan pekerja atau perawat (Manuaba, 2000, dalam Satria, 2013).

Daerah tertinggal sebenarnya kurang diminati oleh tenaga kesehatan untuk mengabdi maupun dalam jangka waktu mengabdi. Berdasarkan hasil penelitian, banyak dokter yang tidak melanjutkan masa PTTnya di rumah sakit maupun menarik diri walau sudah mendaftar. Dampak kurangnya tenaga dokter terhadap pasien adalah pasien mengeluh karena tidak adanya dokter spesialis, pelayan kesehatan tidak memadai dari segi kuantitas pelayanan yang seharusnya sehingga menimbulkan angka rujukan yang tinggi, pasien harus menunggu lebih lama untuk mendapatkan pelayanan dari dokter dan kemungkinan lainnya adalah penanganan pasien yang ditangani oleh dokter melainkan oleh perawat karena dokter sedang berhalangan. Tentunya bukanlah sebuah pelayanan kesehatan yang efektif dan efisien apabila halhal tersebut dialami oleh pasien Jaminan Kesehatan Nasional karena berdampak pada patient safety. Jika di rumah sakit lain, pasien dapat memiliki pilihan terhadap dokter yang akan merawatnya baik dari segi kualifikasi pendidikan maupun faktor hubungan dokter-pasien, namun di R.S TNI AL Samuel J. Moeda Kupang tidak bisa karena pelayanan di ruang perawatan dan poliklinik umum hanya dilayani oleh 2 orang dokter umum.

Tenaga apoteker di R.S TNI AL Samuel J. Moeda Kupang masih kurang. Saat ini hanya terdapat 2 orang apoteker 1 sarjana farmasi dari minimal 4 apoteker untuk rumah sakit tipe C. kekurangan apoteker juga dibuktikan dengan hasil penelitian bahwa instalasi farmasi membutuhkan tambahan tenaga apoteker agar bisa mengontrol manajemen obat di rumah sakit, karena jumlah tenaga apoteker yang kurang, maka tenaga apoteker hanya dapat memenuhi 2 shift pekerjaan saja yaitu pada pagi dan sore hari. Kekurangan tenaga apoteker berdampak beban kerja yang tinggi sehingga seorang apoteker harus mengemban tugas terkait seluruh aspek manajemen logistik di rumah sakit, termasuk pelayanan langsung kepada pasien.

Kondisi ini, barulah kondisi harian dengan kunjungan pasien yang tidak terlalu tinggi, apabila terjadi KLB atau wabah di Kota Kupang maka jumlah tenaga kesehatan baik dokter, keperawatan dan apoteker masih sangat kurang. Jumlah tenaga kesehatan yang ada di R.S TNI AL Samuel J. Moeda Kupang tentunya belum memenuhi klasifikasi kelas perumahsakitan dan berkaitan dengan pelayanan kesehatan yang kurang layak karena tidak dilakukan secara efektif dan efisien dengan cakupan pelayanan yang terbatas bagi pasien di R.S TNI AL Samuel J. Moeda Kupang. Akibatnya, pihak rumah sakit sering merujuk pasien ke fasilitas kesehatan diatasnya.Ini menandakan bahwa aspek kualitas dan jaminan kesehatan untuk pasien tidak terpenuhi padahal negara sudah menjamin bahwa setiap pasien terutama peserta BPJS wajib mendapatkan pelayanan yang layak. 


\section{PENUTUP}

Berdasarkan hasil penelitian dan pembahasan penelitian ini, maka kesimpulan yang dapat dikemukakan adalah :

1. Manajemen mutu Rumah Sakit TNI AL Samuel J. Moeda Kupang dari aspek legalitas rumah sakit belum optimal. Hal ini terlihat dari belum lengkapnya dokumen perizinan yang dimiliki, serta belum semua tenaga kesehatan memiliki Surat Izin Praktek.

2. Manajemen mutu Rumah Sakit TNI AL Samuel J. Moeda Kupang dari aspek tampilan fisik khususnya kelengkapan ruangan pelayanan belum maksimal karena kondisi bangunan baik rawat jalan maupun rawat inap yang sangat terbatas dan belum memenuhi syarat terutama dalam hal penempatan dan kelengkapan ruangan.

3. Manajemen Mutu Rumah Sakit TNI AL Samuel J. Moeda Kupang dari aspek sarana belum optimal karena keterbatasan sarana transportasi terutama mobil operasional belum punya dan sanitasi khusus pengolahan limbah padat belum ada serta pemanfaatan sarana informasi yang belum maksimal dan adanya alat kesehatan yang belum lengakap dan masih terbatas. Di samping itu, banyak alatalat yang belum dikalibrasi dan alat-alat vital bagi pasien yang dalam keadaan rusak.

4. Manajemen mutu Rumah Sakit TNI AL Kupang dalam aspek tenaga kesehatan karena terdapat kekurangan tenaga kesehatan, baik dokter spesialis, dokter umum dan apoteker serta tenaga bidan.

5. Rumah Sakit TNI AL Samuel J. Moeda Kupang belum siap dari aspek obat dalam menyelenggarakan Jaminan Kesehatan Nasional Tahun 2014 karena terdapat sistem pengadaan obat dengan sistem drouping belum jelas serta pengelolaan obat belum maksimal sehingga pengaruh kepada pelayanan obat belum maksimal kepada pasien bagi pasien. Disamping itu juga belum memiliki track record kepuasan pasien sebagai nilai tambah untuk menilai dan mengevaluasi kepuasan pasien.

\section{DAFTAR PUSTAKA}

Akhadi, M. 2012. Pentingnya Kalibrasi Alat Ukur Dalam Kegiatan Medis. http://www.jurnalmedika.com/edisi-tahun-2012/edisi-no-04-vol-xxxvii2012/435-artikel-konsep/890-pentingnya-kalibrasi-alat-ukur-dalam-kegiatanmedis

An-Nafi, Alfi. 2009. Pengaruh Kenyamanan Lingkungan Fisik Ruang Rawat Inap Kelas III terhadap Kepuasan Pasien di RSUI Kustati Surakarta. http://eprints.uns.ac.id/pdf

Anonim. 2010. 520 Rumah Sakit Belum Terakreditasi. http://www.antikorupsi. org/id/content/520-rumah-sakit-belum-terakreditasi (25 Januari 2013)

Arifin, M. 2009. Sanitasi Lingkungan. http://inspeksisanitasi.blogspot .com/2009/07/sanitasi-lingkungan.html 
Anonym. 2013. Pelayanan Kesehatan yang Masih Jauh Dari Layak. http://kebijakankesehatanindonesia.net/policy-brief/2290pelayanankesehatanyangmasih-jauh-dari-layak.html 2006. Pedoman Teknis Sarana dan Prasarana Bangunan Instalasi Rawat Inap (Umum). Jakarta: Depkes RI. . 2007. Peraturan Menteri Kesehatan Republik Indonesia Nomor 512/Menkes/Per/IV/2007 Tentang Izin Praktik dan Pelaksanaan Praktik Kedokteran. Jakarta: Depkes RI

Pasca Sarjana Undana. 2013. Pedoman Penulisan Usulan Penelitian dan Tesis. Kupang: Ilmu Kesehatan Masyarakat Universitas Nusa Cendana Kupang.

Hikmatin, Inni. 2006. Studi Kasus Deskriptif Efektifitas Pelaksanaan Regulasi Perizinan Rumah Sakit Umum. http://repository.unhas.ac.id/jurnalBebanKerjadengan Kinerja.pdf

2013. Keputusan Menteri Kesehatan Republik Indonesia Nomor 328/Menkes/SK/VIII/2013 Tentang Formularium Nasional. Jakarta: Kementerian Kesehatan RI.

Lamuri, Gina. 2013. Fasilitas Minim Pelayanan di R.S TNI AL Samuel J. Moeda KupangBelum Memadai. http://moral-politik.com/2013/08/fasilitas-minimpelayanan-diR.S TNI AL -Kupang -belum-memadai (8 Maret 2013).

Novitasari, D. 2013. Konsep Infeksi Rumah Sakit/Infeksi Nosokomial. http://opiedaliadiary.blogspot.com/2013/II/konsep-infeksi-rumah-sakitinfeksi.html.

Peraturan Pemerintah Republik Indonesia Nomor 32 Tahun 1996 Tentang Tenaga Kesehatan

Peraturan Presiden Nomor 12 Tahun 2013 Tentang Jaminan Kesehatan

Peraturan Presiden Republik Indonesia Nomor 111 Tahun 2013 Tentang Perubahan Atas Peraturan Presiden Nomor 12 Tahun 2013 Tentang Jaminan Kesehatan.

PT ASKES (Persero). 2013. Buku Pegangan Sosialisasi Jaminan Kesehatan Nasional (JKN) dalam Sistem Jaminan Sosial Nasional. Jakarta: PT ASKES (Persero)

R.S TNI AL Kupang . 2013. Profil R.S TNI AL Samuel J. Moeda KupangTahun 2013. Kupang R.S TNI AL Kupang

Sarudji, Didik. 2006. Kesehatan Lingkungan. Sidoarjo: Media Ilmu

Satria, Wa. 2013. Hubungan Beban Kerja Dengan Kinerja Perawat Dalam Mengimplementasikan Patient Safety Di Rumah Sakit Universitas Hassanudin Tahun 2013. http://repository.unhas.ac.id /jurnalBebanKerjadenganKinerja.pdf. Undang-undang Republik Indonesia Nomor 24 Tahun 2011 Tentang Badan Penyelenggara Jaminan Sosial.

Wahyudi, S. 2011. Tanggung Jawab Rumah Sakit Terhadap Kerugian Akibat Kelalaian Tenaga Kesehatan dan Implikasinya. http://fh.unsoed.ac.id/sites/default/files/fileku /dokumen/JDHSeptember2011/1. 